\title{
Endoscopic staging of low-grade gastric MALT lymphoma
}

\author{
M. J. Varas, R. Fabra, R. Abad, J. Turró, J. C. Espinós, D. Bargalló and J. M. Miquel \\ Unit of Echoendoscopy. Centro Médico Teknon. CIMA. Centro Médico Delfos. Barcelona, Spain
}

\begin{abstract}
Introduction: endoscopic ultrasonography (EUS) has already proven useful in the assessment of submucosal lesions, and the staging of gastrointestinal cancer, particularly gastric MALT-type lymphoma. The goal of this paper was EUS staging.

Patients and method: 24 patients (10 females, 14 males) with a median age of 56 years and possibly gastric MALT lymphoma (25 cases) were studied using videoendoscopy, biopsies, and echoendoscopy with 7.5- and 20-MHz radial EUS, and also with 12- and 20-MHz miniprobes (MPs).

Nineteen patients were definitely evaluated ( 7 females, 12 males) as having 20 MALT-type lymphomas, as five patients were post-hoc disregarded when an invasive, high-grade gastric lymphoma (3c) or plasmocytoma (2c) was subsequently demonstrated.

Of these 19 patients, all had T1 lesions except for two with T2 lesions; one patient had a gastroduodenal T1 lymphoma.

Echographic findings with MPs were compared to EUS (gold standard) and histology both before and after eradication. Then, patients were followed up every 1-3-6 months using videoendoscopy and MPs.

Results: echoendoscopy correctly identified T stages in 90\% of cases. MPs identified T stages in $88 \%$ of cases, and $\mathrm{N}$ stages in $33 \%$ of cases, with results being slightly inferior to those obtained with conventional EUS (91 vs. 45\%); they were consequently used for follow-up.

After eradication, all but two patients are in complete remission and have been followed every 1-3-6 months using MPs without echographic abnormalities, except for a patient who relapsed.
\end{abstract}

Key words: Gastric MALT lymphoma. Endoscopic ultrasonography. Transendoscopic echographic miniprobes. Echoendoscopy.

Varas MJ, Fabra R, Abad R, Turró J, Espinós JC, Bargalló D, Miquel M. Endoscopic staging of low-grade gastric MALT lymphoma. Rev Esp Enferm Dig 2006; 98: 189-195.

Recibido: 27-06-05.

Aceptado: 20-10-05.

Correspondencia: M. J. Varas. Centro Médico Teknon. C/ Marquesa Vilallonga, 12, 08017 Barcelona. Fax: 934172 302. e-mail: varas@dr.teknon.es

\section{INTRODUCTION}

Endoscopic ultrasonography (EUS) has proven useful in the assessment of submucosal lesions (1), the staging of gastrointestinal cancers (2), and particularly the staging of low-grade gastric MALT (mucosa-associated lymphoid tissue) lymphoma (2), with sensitivity in the range of $80-95 \%$ (3-7).

Sensitivity to detect suspicious adenopathies is more variable (70\%), and oscillates between 50 and 90\% (3-6); however, diagnostic accuracy in the assessment of lymph-node involvement extent might reach $100 \%$ with the recent introduction of echo guided puncture.

Response to Helicobacter pylori eradicating therapy may also be predicted (7-11). Thus, a lesion extending beyond the submucosa, or in the presence of metastatic adenopathies, will usually not respond to $H$. pylori eradicating therapy, whereas remission rates reach $95 \%$ for lesions involving the mucosa or submucosa (EI1: mucosalsubmucosal T1, N0).

The subject of this paper is EUS staging.

\section{PATIENTS AND METHODS}

Twenty-four patients (10 females, 14 males) aged 18 to 82 years, with a mean age of 56 years, and with suspected gastric MALT lymphoma (25 cases) were studied by videoendoscopy and biopsy, and staged according to the TNM classification using EUS with a $7.5 \mathrm{MHz}, 20$ MHz Radial Olympus, and both radial and linear, 12 and $20 \mathrm{MHz}$ (Fuji SP-701) (2.6 mm) miniprobes introduced through the videoendoscope's working channel (2.8 $\mathrm{mm})$. We are recently using Olympus UM-DP $12-25 \mathrm{R}$ and 20-25R, 12 and $20 \mathrm{MHz}$, MPs with a DPR system.

Endoscopy and biopsies were performed using a Fujinon EG-200 FP and EG-400 FP videoendoscope. An informed consent was always required. 
MP findings were compared to those of radial EUS (gold standard) and histology, both before and after $H$. pylori eradication.

Inclusion criteria included: patients with low-grade MALT lymphoma, $H$. pylori positivity; exclusion criteria included: high-grade MALT lymphoma, IBD, and human immunodeficiency virus positivity.

Nineteen patients were definitely assessed ( 7 females, 12 males), as five patients were dispensed with when a high-grade, invasive gastric lymphoma (3c) or plasmocytoma (2c) was demonstrated post-hoc, with one of them dying.

The 1997 TNM classification (12) for the staging of gastric adenocarcinoma was used to study every lymphoma's penetration into the gastric wall: $\mathrm{T} 1$, mucosal and submucosal invasion; T2, muscularis propria invasion; T3, invasion beyond the muscularis propria and into the serose layer; T4, invasion of adjacent structures (Figs. 1-5).

N0, no adenopathies; N1, regional adenopathies.

Regional metastatic adenopathies were defined as homogeneous, hypoechogenic, rounded nodules greater than $5 \mathrm{~mm}$ in size. In no case was an echo guided puncture performed.

Following eradication using triple therapy for 7-14 days, patients were controlled every 1-3-6 months with videoendoscopy and miniprobes.

Out of 19 patients, all were T1 except for two, who were T2, while another female patient had a gastroduodenal T1 MALT lymphoma (13). In all, 20 cases of MALT lesions in 19 patients, since one patient had both gastric and duodenal involvement. Frequency and sensitivity were analyzed using standard formulas.

\section{RESULTS}

Echoendoscopy with EUS and/or MPs correctly identified $\mathrm{T}$ stages in $90 \%$ of cases $(18 / 20)$, and $\mathrm{N}$ stages in $40 \%$ of cases $(8 / 20)$ (Table I).

Table I. Findings in 25 cases ( 24 patients -1 patient with two lesions, gastric and duodenal)

\begin{tabular}{ll}
\hline 25 cases possible & \\
5 cases excluded & \\
20 cases with echoendoscopy (EUS/MP) & S: $90 \%(18 / 20)$ \\
11 cases with EUS & S: $91 \%(10 / 11)$ \\
9 cases with MP & S: $88 \%(8 / 9)$ \\
\hline
\end{tabular}

MPs identified $\mathrm{T}$ stage (all were T1, except two with $\mathrm{T} 2$ ) in $88 \%$ of cases, and $\mathrm{N}$ stage in $33 \%$ of cases, with results being slightly inferior to those obtained with conventional radial EUS (91 and 45\%), and were thus used for follow-up. Adenopathies detected were always greater than $5 \mathrm{~mm}$.

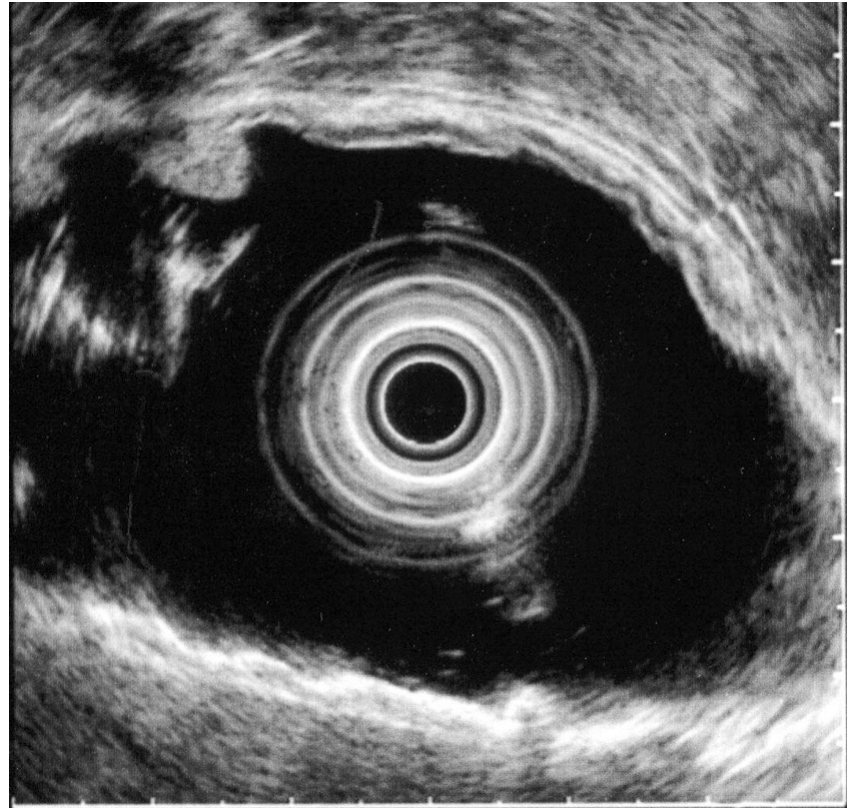

Fig. 1.- 7.5-MHz EUS: normal layers in a T1NO patient in remission. USE con 7,5 MHz: capas normales de un paciente T1NO en remisión.

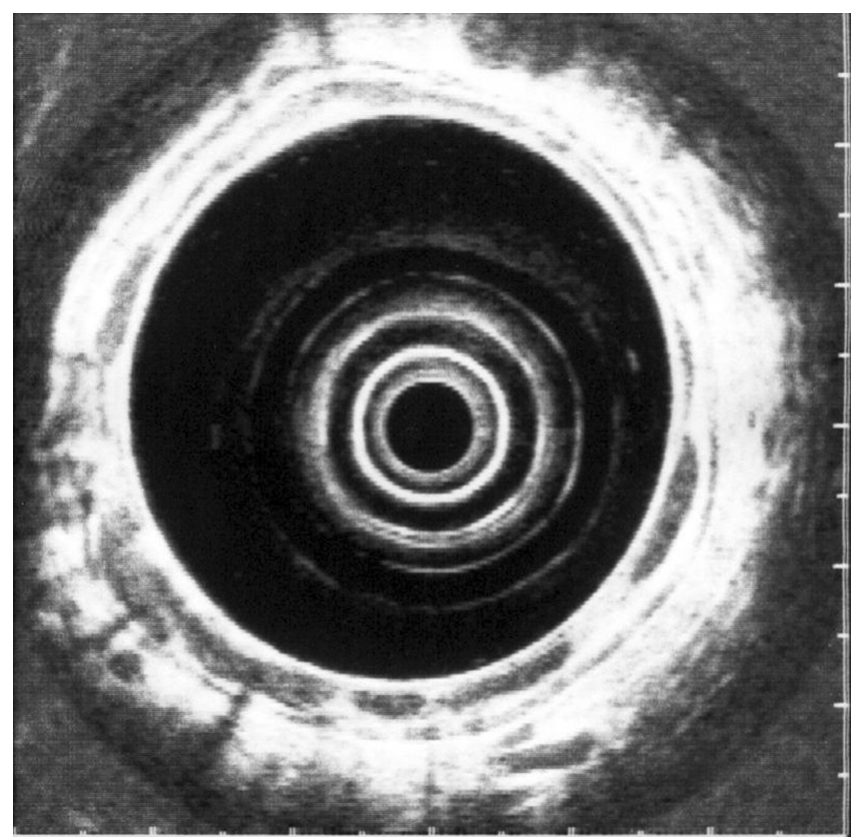

Fig. 2.- 20-MHz EUS: hypoechogenic nodules within the mucosa (T1N1).

USE con $20 \mathrm{MHz}$ : nódulos hipoecogénicos situados en la mucosa (T1N1).

Following eradication, all T1s (EI1) but three (81\%) are in full remission and have been followed every 1-3-6 months using MPs with no echographic abnormalities, except for a female patient who had a relapse during follow-up. No complications occurred. 


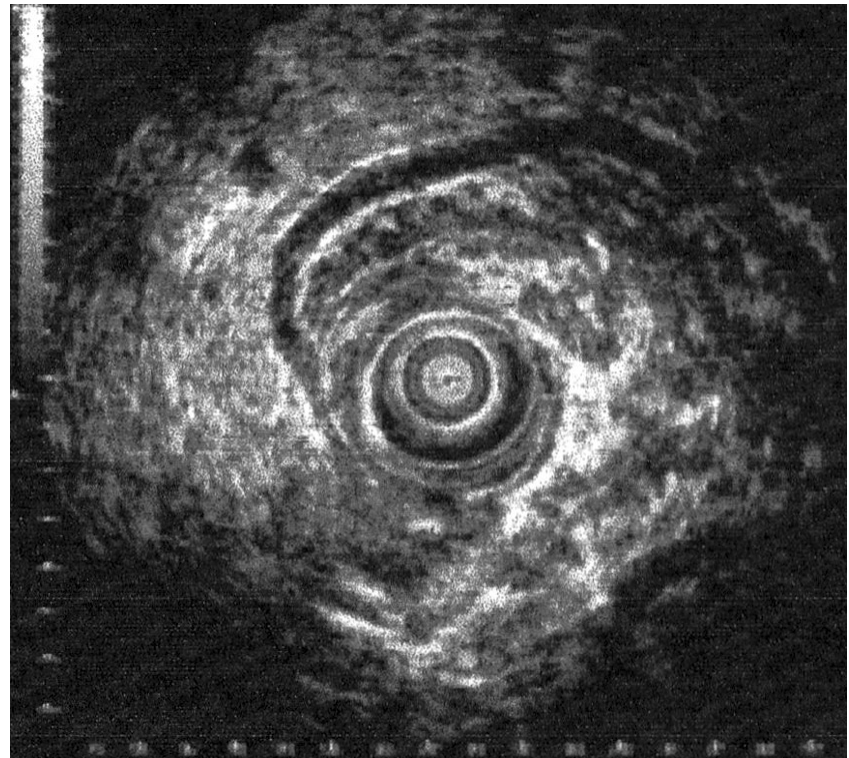

Fig. 3.- 12-MHz MP: hypoechogenic mass involving the mucosa and submucosa without infiltration of the muscularis propria (T1-N1).

MS de $12 \mathrm{MHz}$ : masa hipoecogénica que afecta a mucosa y submucosa sin infiltrar la muscular propia (T1-N1).

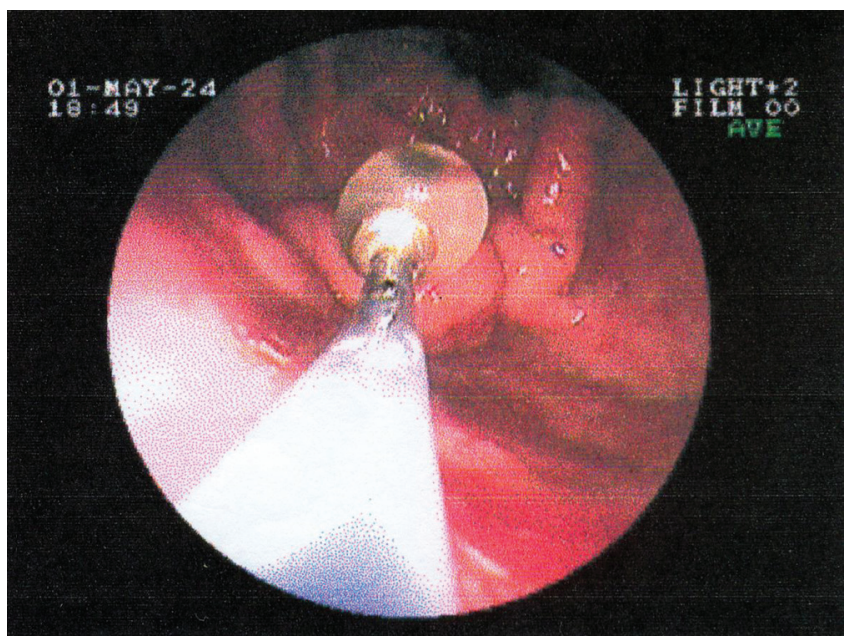

Fig. 4.- Endoscopic image from the above patient using a videoendoscope and a 7.5-MHz MP.

Imagen endoscópica del paciente anterior explorado con un videoendoscopio y una MS de $7.5 \mathrm{MHz}$.

\section{DISCUSSION}

Conventional radial EUS assesses $\mathrm{T}$ stage with a precision and sensitivity around $85-90 \%$, and $\mathrm{N}$ stage with a sensitivity around 70\% (60-90\%) (2-7). In our patients it was 90 and $40 \%$, respectively.

Initial layer involvement and the absence of adenopathies directs towards a low-grade MALT lymphoma, whereas massive transwall infiltration and the presence of adenopathies usually suggests a high-grade

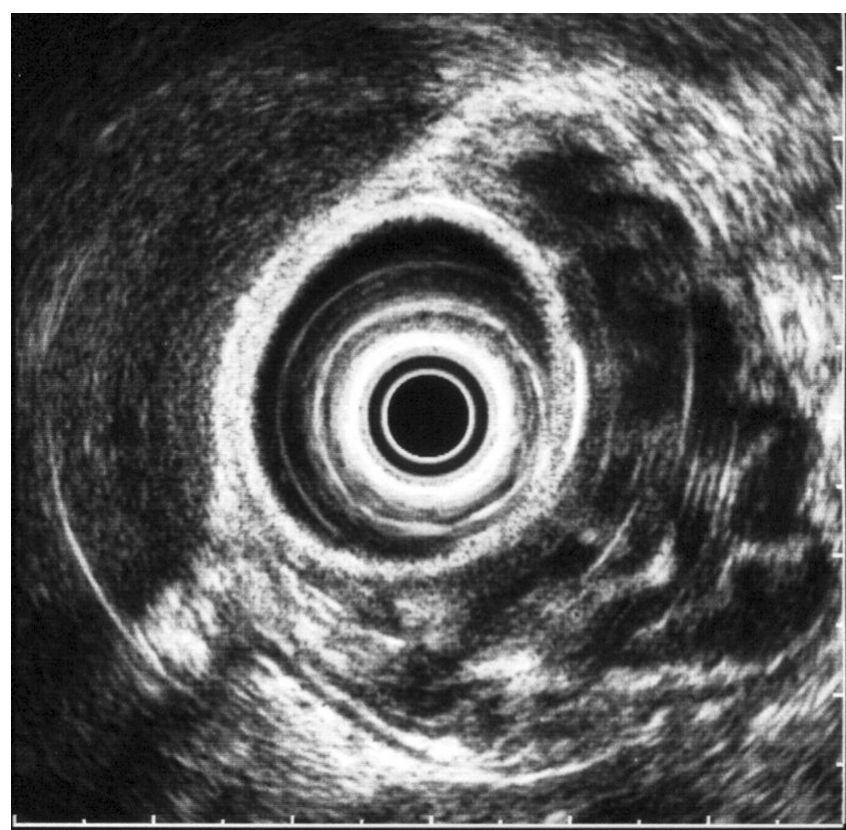

Fig. 5.- 7.5-MHz EUS: a gastric T2-NO MALT lymphoma on the right side.

USE con 7.5 MHz: a la derecha MALT gástrico T2-NO.

lymphoma (8). According to these parameters EUS may predict response to treatment (8-10). With early diagnosis and treatment the prognosis of patients with low-grade gastric MALT lymphoma is usually good.

Endoscopic ultrasonography with an MP has a diagnostic accuracy and precise prognostic assessment similar to conventional EUS. Effectively, Lügering et al. (11) studied 39 patients with gastric MALT lymphomas smaller than $4 \mathrm{~cm}, 15$ before treatment and 24 during followup; by comparing conventional EUS to a $12-\mathrm{MHz} \mathrm{MP}$, in the assessment of T stage they obtained 80 versus $86 \%$, and in the assessment of $\mathrm{N}$ stage they obtained 60 versus $53 \%$, with differences not reaching statistical significance. During follow-up, when MP findings were normal (15 cases), a subsequent histologic examination confirmed full remission in all patients, while hypoechogenic lesions within the mucosa or submucosa were detected in 9 cases, with only 4 cases receiving histologic confirmation for relapse (44.5\%). In our patients, follow-up with an MP demonstrated no echographic abnormalities, which correlated well to negative histologic findings, except in a patient who had relapsing disease. When comparing EUS and MP before eradicating therapy, we obtained 91 versus $88 \%$ for T staging, and 45 versus $33 \%$ for $\mathrm{N}$ staging. Adenopathies identified were always smaller than $1 \mathrm{~cm}$.

Ultrasonographic studies using an MP may be performed during the endoscopic procedure itself -both for diagnosis and follow-up- when a gastric lesion is suspected, which may be biopsied concomitantly. No complications occurred. 
Conventional EUS requires a re-examination following endoscopy and biopsy. Some times balloon compression makes difficult the study of superficial lesions, whereas MPs are precisely indicated in this type of lesions, particularly high-frequency MPs, which have a very high close-up resolution at the expense of scarce ultrasound penetration.

However, the greatest limitation of conventional EUS is advanced, stenosing lymphomas. In such rare cases, MPs offer a better $\mathrm{T}$ staging, but poorer $\mathrm{N}$ staging capability (11).

We think that MPs may be used in the staging of lowgrade gastric MALT-type lymphoma during the endoscopic procedure, and particularly during follow-up, with a high sensitivity similar to that obtained in previous studies with conventional EUS. Its main limitation would be $\mathrm{N}$ staging, which may be compensated for by using either multi-frequency or low-frequency/high penetration MPs.

By appropriately selecting patients long-term remission could be a fact approaching 100 versus $80 \%$ as reported by some literature review (14). Recently, Diz-Lois et al. (15) reported on 14 EI1 (MALT involvement only up to the submucosa) patients, with $71 \%$ full remissions after eradication, and $100 \%$ cures following eradication and chemotherapy in cases not reaching a full remission. In our EI1 cases remission was complete in $81 \%$, with cure in also $100 \%$. Five-year survival is usually above $70 \%(16,17)$.

While the Italian experience $(18,19)$ with 76 initial cases reports very successful eradication results as a function of staging (relevant remission for T1N0 stages), with an accuracy of $95 \%$, sensitivity of $89 \%$, and specificity of $97 \%$ for EUS in the staging procedure, such is not the case with the German experience (20). Fischbach et al. (20), in a multicenter study of 80 cases with several work groups, conclude that EUS staging was only successful in 53\% of cases, as EUS underestimates the diagnosis of adenopathies. Similar results have been reported by only one group (21). These difficulties may improve using echo guided puncture to tell inflammatory from metastatic adenopathies; however, even in such case percentages would not reach $100 \%$, as a recent Japanese paper quotes $94 \%$ positives (22) with a $19-\mathrm{G}$ needle.

\section{REFERENCES}

1. Varas MJ, Maluenda MD, Pou JM, Abad R, Turró J, Espinós JC. Valor de la ultrasonografía endoscópica en el estudio de los tumores submucosos del tracto digestivo. Gastroenterol y Hepatol 1998; 21: 1214.

2. Maluenda MD, Pou JM, Varas MJ, Turró J, Abad R, Espinós JC.
Ecoendoscopia: implicaciones clínicas después de un periodo de más de 16 años de existencia. Rev Esp Enferm Dig 1999; 91: 209-22.

3. Fusjishima H, Misawa T, Maruoka A, et al. Staging and follow-up of primary gastric lymphoma by endoscopic ultrasonography. Am J Gastroenterol 1991; 86: 719-24.

4. Schüder G, Hildebrant U, Kreibler-Haag D, Seitz G, Feifel G. Role of endosonography in the surgical management of non-Hodgkin's lymphoma of the stomach. Endoscopy 1993; 25: 509-12.

5. Palazzo L, Roseau G, Ruskone A, et al. Endoscopic ultrasonography in the local staging of primary gastric lymphoma. Endoscopy 1993; 25: 502-8.

6. Suekane H, Iida M, Yao T, et al. Endoscopic ultrasonography in primary gastric lymphoma: a correlation with endoscopic and histologic findings. Gastrointest Endosc 1993; 39: 139-45.

7. Levy M, Hammel P, Lamarque D, et al. Endoscopic ultrasonography for the initial staging and follow up in patients with low grade gastric lymphoma of mucosa-associated lymphoid tissue treated medically. Gastrointest Endosc 1997; 46: 328-33.

8. Sackmann M, Morgner A, Rudolph B, et al. Regression of gastric MALT lymphoma after eradication of Helicobacter pylori is predicted by endosonographic staging. MALT Lymphoma Study Group. Gastroenterology 1997; 113: 1087-90.

9. Nobre-Leitao C, Lage P, Cravo M, et al. Treatment of gastric MALT lymphoma by Helicobacter pylori eradicaction: a study controlled by endoscopic ultrasonography. Am J Gastroeterol 1998; 93: 732-6.

10. Nakamura S, Matsumoto T, Suekane H, et al. Predictive value of endoscopic ultrasonography for regression of gastric low-grade and high-grade MALT lymphomas after eradication of Helicobacter pylori. Gut 2001; 48: 454-60.

11. Lügering N, Menzel J, Kucharzik T, et al. Impact of Miniprobes compared to conventional endosonography in the staging of low-grade gastric MALT lymphoma. Endoscopy 2001; 33: 832-7.

12. The new TNM classification in Gastroenterology (1997). Endoscopy 1998; 30: 645 .

13. Nakamura S, Matsumoto T, Nakamura S, et al. Duodenal mucosa-associated lymphoid tissue lymphoma treated by eradication of Helicobacter pylori: report of 2 cases including EUS findings. Gastrointest Endosc 2001; 54: 772-5.

14. Wotherspoon AC. A critical review of the effect of Helicobacter pylori eradication on gastric Malt Lymphoma. Curr Gastroenterol Rep 2000; $2:$ 494-8.

15. Diz-Lois Palomares MT, Souto Ruzo J, Yáñez López JA, Álvarez García A, Arnal Monreal F, Vázquez-Iglesias JL. Lifomas gástricos MALT en estadio precoz: erradicación de H. pylori y evolución. Rev Esp Enferm Dig 2002; 94: 669-73.

16. Morgner A, Thiede C, Bayerdorffer E. Long term follow-up of gastric MALT lymphoma after H. pylori eradication. Curr Gastroenterol Rep 2001; 3: 516-22.

17. Hopffner N, Lahme T, Gilly J, Menzel J, Kock P, Foerster EC. Value of endosonography in diagnostic staging of primary gastric lymphoma (Malt type). Med Klin 2003; 98: 313-7.

18. Fusaroli P, Buscarini E, Parente F, et al. Prognosis factors for response to antibiotic therapy of low-grade gastric MALT lymphoma: the importance or TNM staging by endoscopic ultrasonography. Digest Liver Dis 2001; 33: A5.

19. Caletti G, Fusaroli P, Togliani T. EUS in MALT lymphoma. Gatrointest Endosc 2002; 56 (Supl.): S21-S26.

20. Fischbach W, Goebeler-Kolve ME, Greiner A. Diagnostic accuracy of EUS in the local staging of primary gastric lymphoma: results of a prospective, multicenter study comparing EUS with histopathologic stage. Gastrointest Endosc 2002; 56: 696-700.

21. Puspok A, Rederer M, Chott A, et al. Endoscopic ultrasound in the follow up and response assessment of patients with primary gastric lymphoma. Gut 2002; 51: 691-4.

22. Yasuda I, Nakai M, Kojima Y, et al. EUS-FNA for lymphadenopathy in cases of suspected lymphoma. Diges Endoscopy 2004; 16 (Supl.): A85. 